\title{
HPMA Copolymer-Based Polymer Conjugates for the Delivery and Controlled Release of Retinoids
}

\author{
O. LIDICKÝ ${ }^{1}$, M. ŠÍROVÁ ${ }^{2}$ T. ETRYCH ${ }^{1}$ \\ ${ }^{1}$ Institute of Macromolecular Chemistry of the Czech Academy of Sciences, Prague, Czech \\ Republic, ${ }^{2}$ Institute of Microbiology of the Czech Academy of Sciences, Prague, Czech Republic
}

Received July 14, 2016

Accepted July 14, 2016

\section{Summary}

In this paper, we describe the synthesis, physicochemical characterization, drug release kinetics and preliminary biological evaluation of several $N$-(2-hydroxypropyl)methacrylamide (HPMA)-based polymer-retinoid conjugates designed for solid tumor immunotherapy. The conjugates are supposed to inhibit the immunosuppressive activity of myeloid-derived suppressor cells (MDSC) accumulated in the solid tumor microenvironment. All-trans retinoic acid (ATRA) was derivatized to hydrazide (AtrHy) and then attached to the polymer backbone via a spacer that is stable at the normal pH of blood (7.4) and hydrolytically degradable in mildly acidic environments (e.g. in endosomes or lysosomes, $\quad \mathrm{pH}$ 5.0-6.5). Polymer-AtrHy conjugates were designed to achieve prolonged blood circulation and release of the immunomodulator intracellularly or extracellularly in solid tumor tissue. Three types of polymer precursors, differing in the structure of the keto acid-containing side chains, were synthesized. A linkage susceptible to hydrolytic cleavage was formed by the conjugation reaction of the carbonyl groupterminated side chains of the polymer precursors with the hydrazide group of a drug derivative. In vitro incubation of the conjugates in buffers resulted in much faster release of the drugs or their derivatives from the polymer at $\mathrm{pH} 5.0$ than at $\mathrm{pH} 7.4$, with the rate depending on the detailed structure of the spacer. Both the AtrHy derivative and its polymer conjugates showed the ability to induce the differentiation of retinoid-responsive HL-60 cells, thus demonstrating the required biological activity.

\section{Key words}

Polymer conjugate - Retinoid • HPMA - Controlled release • Myeloid-derived suppressor cells

\section{Corresponding author}

T. Etrych, Institute of Macromolecular Chemistry of the Czech Academy of Sciences, Heyrovského nám. 2, 16206 Prague 6, Czech Republic. E-mail: etrych@imc.cas.cz

\section{Introduction}

In the last 30 years, many studies have focused on drug delivery to solid tumors using water-soluble $\mathrm{N}$-(2hydroxypropyl)methacrylamide (HPMA)-based polymer carriers. The advantages of such systems include the increased solubility of drugs after attachment to the polymer backbone, specific tumor targeting, reduction of drug side effects and significant prolongation of the blood circulation (Kopeček and Kopečková 2010, Ulbrich and Šubr 2010). Thanks to the increased molecular weight, the delivery system is passively targeted and accumulated in the tumor tissue due to the enhanced permeability and retention effect (EPR) (Fang et al. 2011, Seymour et al. 1995). Drugs can be covalently attached to the polymer carrier via various stimulus-sensitive spacers, e.g. spacers containing $\mathrm{pH}$-sensitive hydrazone bonds, enzymatically degradable oligopeptides or reductively degradable disulfide bonds, which are designed to control the release of the drug from the carrier (Wicki et al. 2015).

Many anti-cancer drugs have been developed, but their therapeutic use still remains rather ineffective. One of the reasons is the frequent presence of various mechanisms that suppress anti-cancer immune responses, impairing the T-cell-dependent cytotoxic immune responses and allowing the tumor to escape the immunemediated control. The current trend in cancer therapy is to counteract the suppressive mechanisms and to restore 
the anti-cancer immune response (Kapadia et al. 2015) using synergistic combinations of anti-cancer treatment and immunomodulation. This strategy enables the generation of a specific anti-cancer immune response and the induction of persistent immunological memory (Vanneman and Dranoff 2012).

One of the suppressive mechanisms contributing to tumor-induced immune escape is mediated by a heterologous population of myeloid-derived suppressor cells (MDSC). They comprise immature granulocytes, macrophages, and dendritic cells and are endowed with a robust suppressive capacity (Gabrilovich and Nagaraj 2009, Ostrand-Rosenberg et al. 2009). MDSCs migrate from bone marrow through the blood and accumulate in secondary lymphoid organs and tumors. In normal healthy individuals, the immature myeloid cells differentiate to their mature functional counterparts. In the tumor microenvironment, their normal differentiation is prevented, and the cells acquire a potent suppressive activity towards both innate and adaptive immune responses via multiple mechanisms. These MDSCs are responsible for the suppression of $\mathrm{T}$ cells and natural killer (NK) cells. MDSCs sustain tumor progression by providing a favorable microenvironment in which transformed tumor cells can proliferate, acquire new mutations, and evade host immunosurveillance (Serafini 2013). MDSCs also contribute to tumor neoangiogenesis (Dolcetti et al. 2008). Increase in the systemic circulation of MDSCs is often associated with poor patient prognosis in various cancers (Weide et al. 2014). Therefore, MDSCs have attracted considerable interest as potential targets in the development of cancer therapies that may abrogate tumor-associated immunosuppression (Ugel et al. 2009). MDSC targeting in experimental murine tumors using anti-Gr-1 antibody demonstrated significant improvement in immune response, providing a proof of concept that reducing MDSC accumulation or suppressive function may potentiate anti-tumor therapy (Srivastava et al. 2012).

One of the drugs that could be used to reduce the amount of MDSCs is all-trans retinoic acid (ATRA). In tumor-bearing mice, the $\mathrm{CD}^{+}-$and $\mathrm{CD}^{+}$-mediated tumor-specific immune responses were noticeably improved after ATRA treatment. ATRA induces the differentiation of MDSCs into mature myeloid cells (macrophages, dendritic cells, or granulocytes) by the upregulation of glutathione synthesis and down-regulation of reactive oxygen species (ROS) (Kusmartsev et al. 2003, Nefedova et al. 2007). The treatment of mice with
ATRA decreased the spleen MDSCs, reduced the blood MDSCs in patients with renal carcinoma, and reversed the immune suppression (Mirza et al. 2006, Kusmartsev et al. 2008). ATRA is a hydrophobic compound that is UV and oxygen sensitive. Moreover, as a low-molecularweight agent, ATRA has no selectivity towards tumor tissue. Thus, its applicability as a selective treatment agent capable of modulating MDSC activity in solid tumors is limited. Its stability, solubility, bioavailability and biodistribution could be significantly improved by using nanocarriers. Several methods have been published: the use of micelles (Fattahi et al. 2012) or microspheres encapsulated with ATRA (Jeong et al. 2003), a solid lipid nanoparticle powder formulation of ATRA (Lim et al. 2004), or block copolymer nanoparticles loaded with ATRA (Tiwari et al. 2011).

In this work, we have focused on the preparation of polymer systems based on the HPMA copolymers that are suitable to covalently bound ATRA, deliver it and release in controlled manner within solid tumor tissue. The polymer-based tumor-specific delivery of ATRA is designed for tumor-targeted immunomodulation that could potentially be explored to eliminate immune suppression and to potentiate anti-tumor therapy.

\section{Materials and Methods}

\section{Chemicals}

1-Aminopropan-2-ol, methacryloyl chloride, 2,2'-azobis(isobutyronitrile) (AIBN), 4,4'-Azobis(4cyanovaleric acid) (ABIK), dimethylformamide (DMF), 1-ethyl-3-(3-dimethylaminopropyl)carbodiimide (EDC), $N$-hydroxysuccinimide, thiazolidine-2-thion (TT), orthophthalaldehyde (OPA), $N$-ethyldiisopropylamine, dimethyl sulfoxide (DMSO), 4-cyano-4(phenylcarbonothioylthio)pentanoic acid (ACVA-RAFT), 4-oxo-pentanoic acid (OPe) and $N, N^{\prime}$-dicyclohexylcarbodiimide (DCC) were purchased from Fluka. 2,4,6-Trinitrobenzene-1-sulfonic acid (TNBSA) was purchased from Serva. $N$-(tert-butoxycarbonylaminopropyl)methacrylamide (APMA-BOC) were purchased from Polysciences. All-trans retinoic acid (ATRA) was purchased from Enzo life science. 4-oxo-4(2-pyridyl)butyric acid (OPB) and 5-cyclohexyl-5oxovaleric acid $(\mathrm{COV})$ were purchased from Rieke ${ }^{\circledR}$ Fine chemicals. RPMI 1640 medium, L-glutamine and antibiotics (penicillin/streptomycin) were purchased from Sigma-Aldrich. Fetal calf serum (FCS) was purchased from Invitrogen. 


\section{Synthesis of monomer}

HPMA was synthesized as described in (Ulbrich et al. 2000); elemental analysis: calc./found $\mathrm{C}=58.72 / 58.98 \% ; \mathrm{H}=9.15 / 9.18 \% ; \mathrm{N}=9.78 / 9.82 \%$.

\section{Synthesis of polymer precursor}

Polymer precursor Pol was prepared by controlled RAFT radical polymerization carried out at $70{ }^{\circ} \mathrm{C}$ for $17 \mathrm{~h}$ using $\mathrm{ABIK}$ as an initiator and ACVARAFT as a RAFT chain transfer agent in mixture of dioxane:distilled water $1: 2$ [dioxane $(3.88 \mathrm{ml})$ and distilled water $(7.76 \mathrm{ml})]$ as the solvent. The molar ratio of HPMA and APMA-BOC monomers was 9:1; 10.49 mmol HPMA $(1,500 \mathrm{mg})$ and $1.17 \mathrm{mmol}$ APMABOC $(270 \mathrm{mg})$. Afterward the polymer was obtained by precipitation in aceton:diethyl ether (2:1). Dithiobenzoate chain-terminating groups were removed by reaction of polymer precursor with $\mathrm{AIBN}$ in $\mathrm{DMF}$ at $80^{\circ} \mathrm{C}$ for 3 hours. Polymer product was isolated by precipitation in aceton and reprecipitation in diethyl ether:aceton $(1: 2)$ mixture. Protecting BOC groups were removed by dissolving the polymer precursor overnight in methanol/HCl solution. Amount of amino groups in polymer precursor Pol- $\mathrm{NH}_{2}$ was determined using UV/VIS spectroscopy via modified TNBSA assay as described previously (Etrych et al. 2001) using absorption coefficient $\varepsilon_{420}=11,550 \mathrm{l} \cdot \mathrm{mol}^{-1} \cdot \mathrm{cm}^{-1}$.

\section{Synthesis of polymer Pol-OPB}

The synthesis of the polymer precursor containing side chains terminating in the OPB moiety was performed in two steps. Briefly, in the first step, the thioazolidin-2-thion (TT) amide of OPB was prepared using carbodiimide chemistry. OPB (31 mg, $0.173 \mathrm{mmol}$ ) was dissolved in $600 \mu \mathrm{l}$ of DCM and mixed with a solution of EDC $(33.3 \mathrm{mg}, 0.214 \mathrm{mmol})$ and TT (21 mg, $0.176 \mathrm{mmol}$ ) in $1.7 \mathrm{~m}$ of DCM. The reaction was monitored using an HPLC Shimadzu system equipped with a DAD detector. After $3 \mathrm{~h}$, OPB-TT was purified by extraction with $\mathrm{NaHCO}_{3}$ in $\mathrm{H}_{2} \mathrm{O}$ (acetate buffer 5.5), filtered and dried with $\mathrm{Na}_{2} \mathrm{SO}_{4}$, evaporated and dissolved in methanol. The solution of OPB-TT in DMF (41 mg) was afterward immediately added to the polymer precursor Pol- $\mathrm{NH}_{2}(160 \mathrm{mg})$ dissolved in $8.5 \mathrm{ml}$ of DMF and left overnight at $8{ }^{\circ} \mathrm{C}$. The polymer Pol-OPB was purified from low-molecular impurities by column chromatography using Sephadex LH-20 with methanol as the mobile phase. The product was obtained by precipitation into diethyl ether. The amount of OPB was determined indirectly based on the amount of amino groups on the polymer precursor before and after the reaction with OPB-TT. Finally, the remaining amino groups in Pol-OPB were reacted with acetic anhydride to block them before the subsequent reactions. Yield: $158 \mathrm{mg}(91 \%)$.

\section{Synthesis of polymer Pol-COV}

The synthesis of the polymer precursor containing side chains terminating in COV was conducted in two steps, as described above. Briefly, in the first step, the TT containing reactive intermediate product of $\mathrm{COV}$ was prepared by the same method described above, using EDC as the carbodiimide coupling agent. The solution of COV-TT $(76.8 \mathrm{mg}$ in $1 \mathrm{ml}$ of DMF) was afterward immediately added to the solution of polymer precursor Pol- $\mathrm{NH}_{2}$ (300 $\mathrm{mg}$ in $6 \mathrm{ml}$ of DMF) followed by the addition of DIPEA $(27 \mu \mathrm{l})$ and left overnight at $8^{\circ} \mathrm{C}$. After the removal of the lowmolecular-weight impurities by column chromatography and precipitation into diethylether, the amount of $\mathrm{COV}$ was determined indirectly as described for Pol-OPB. Finally, the remaining amino groups in Pol-COV were reacted with acetic anhydride to block them before the subsequent reactions. Yield: $264 \mathrm{mg}$ (83\%).

\section{Synthesis of polymer Pol-OPe}

In the first step, the amino reactive 1-(2-thioxothiazolidin-3-yl)-pentane-1,4-dione (OPe-TT) was prepared as described previously (Šubr et al. 2014). Briefly, 4-oxo-pentanoic acid and TT were dissolved in dichloromethane (DCM), and EDC was added as a coupling agent under vigorous stirring. The reaction was stirred for $3 \mathrm{~h}$ at room temperature, and the product was extracted with distilled water and 2 wt. $\% \mathrm{NaHCO}_{3}$ in aqueous solution. The final product was obtained by crystallization from ethyl acetate. Elemental analysis: calc./found $\mathrm{C}=44.22 / 44.34 \% ; \quad \mathrm{H}=5.10 / 5.23 \% ; \quad \mathrm{N}=6.45 / 6.47 \%$; $\mathrm{S}=29.51 / 28.52 \%$; ${ }^{1} \mathrm{H}$ NMR $300 \mathrm{MHz}$ (DMSO, $296 \mathrm{~K}$ ). Polymer Pol-OPe was prepared by the reaction of polymer precursor Pol- $\mathrm{NH}_{2}(200 \mathrm{mg})$ dissolved in $3 \mathrm{ml}$ of DMF with OPe-TT (100 mg) dissolved in $1 \mathrm{ml}$ of DMF, carried out in the presence of $15.2 \mu \mathrm{l}$ of DIPEA. After $3 \mathrm{~h}$, the polymer was purified from low-molecular-weight impurities by liquid chromatography using a column filled with Sephadex LH-20 with methanol as the eluent. The polymer Pol-OPe was precipitated into ethyl acetate. Yield: $190 \mathrm{mg}$ (73\%). 
Synthesis of hydrazide derivative of ATRA

All trans-retinoic acid $(116 \mathrm{mg}, 0.386 \mathrm{~mol})$, DCC $(87.6 \mathrm{mg}, 0.425 \mathrm{~mol})$ and $N$-hydroxysuccinimide $(47 \mathrm{mg}, 0.408 \mathrm{~mol})$ were dissolved in mixture of DCM $(1 \mathrm{ml})$ and DMF $(0.1 \mathrm{ml})$ at $\mathrm{RT}$ in the dark under an argon atmosphere. After 96 hours, the precipitated dicyclohexylurea was filtrated out, and hydrazine hydrate (58 $\mathrm{mg}, 1.8 \mathrm{mmol}$ ) was added dropwise. The reaction was carried out using an HPLC system as described above. After one hour, impurities were removed by column chromatography on silica gel using a mixture of ethyl acetate:hexane (20:3) as the mobile phase. The second fraction containing the products was collected, and the ATRA hydrazide derivative (AtrHy) was obtained after evaporation of the solvent. Yield and characterization: $107 \mathrm{mg} \quad(88 \%)$, elemental analysis: calc./found $\mathrm{C}=76.39 / 73.66 \% ; \quad \mathrm{H}=9.62 / 10.52 \% ; \quad \mathrm{N}=8.91 / 9.4 \%$; $\mathrm{O}=5.09 / 6.48 \%$; ${ }^{1} \mathrm{H}$ NMR $300 \mathrm{MHz}\left(\mathrm{CDCl}_{3}, 295 \mathrm{~K}\right)$.

\section{Synthesis of polymer conjugates containing AtrHy}

Polymer conjugates Pol-OPe-AtrHy, Pol-OPBAtrHy and Pol-COV-AtrHy containing the AtrHy derivative were prepared by the reaction of the hydrazide group of the ATRA derivative with the respective polymer precursors containing keto groups. The reaction was carried out in methanol with the addition of acetic acid $(40 \mu \mathrm{l} / \mathrm{ml}$ methanol) in the dark and under inert atmosphere (Etrych et al. 2002). The unreacted AtrHy derivative was removed from the polymer conjugates by the precipitation of the polymer conjugate into diethyl ether. Yield: $93 \mathrm{mg}$ Pol-OPe-AtrHy containing $8.6 \mathrm{mg}$ AtrHy (75\%), $87 \mathrm{mg}$ Pol-OPB-AtrHy containing $7.2 \mathrm{mg}$ AtrHy (56.8\%), and $35 \mathrm{mg}$ Pol-COV-AtrHy containing $2.7 \mathrm{mg}$ AtrHy (62.6\%).

\section{Physico-chemical characterization}

Content of ATRA or its derivate was determined by UV/Vis spectrophotometry on Helios $\alpha$ (Thermo Fisher Scientific, Walthan, MA, USA) spectrophotometer $\left(\varepsilon_{363}=22,6901 \cdot \mathrm{mol}^{-1} \cdot \mathrm{cm}^{-1}\right.$ in methanol). Determination of molecular weight and dispersity of polymer precursors and polymer conjugates was carried out with an HPLC Shimadzu system equipped with RI, UV, and multi-angle light scattering DAWN EOS (Wyatt, USA) detectors using $0.3 \mathrm{M}$ acetate buffer $\mathrm{pH} 6.5$ and GPC column TSKgel G3000SWxl $(300 \times 7.8 \mathrm{~mm} ; 5 \mu \mathrm{m})$; mobile phase containing $20 \%$ of $0.3 \mathrm{M}$ acetate buffer $\left(\mathrm{CH}_{3} \mathrm{COONa} /\right.$ $\mathrm{CH}_{3} \mathrm{COOH} ; \mathrm{pH} 6.5 ; 0.5 \mathrm{~g} / 1 \mathrm{NaN}_{3}$ ) and $80 \%$ of methanol; flow rate $0.5 \mathrm{ml} / \mathrm{min})$. Hydrodynamic radius $\left(\mathrm{R}_{\mathrm{h}}\right)$ of polymer samples dissolved in phosphate buffer $(0.1 \mathrm{M}$, with $0.05 \mathrm{M} \mathrm{NaCl}$; polymer concentrations: $0.01 \mathrm{~g} / \mathrm{ml}^{-1}$ ) was measured at $25^{\circ} \mathrm{C}$ by dynamic light scattering (DLS) using Nano-ZS instrument Zetasizer (ZEN3600, Malvern) as described previously (Chytil et al. 2010). The values were a mean of at least five independent measurements.

\section{In vitro release study}

The rate of AtrHy release from the polymer conjugates was measured in phosphate buffers modeling the environment in endosomes and lysosomes (pH 5.0) or in the blood stream ( $\mathrm{pH} 7.4)$ at $37^{\circ} \mathrm{C}$ using an HPLC Shimadzu system equipped with a DAD detector and reverse phase Chromolith $\circledast$ HR RP-18 endcapped 100-4.6 HPLC column. The appropriate polymer conjugate was dissolved in buffer at a final concentration equivalent to $5 \mu \mathrm{M}$ AtrHy. At predetermined time intervals, $20 \mu \mathrm{l}$ of the solution were analyzed by HPLC to determine the contents of free, released, and polymer-bound AtrHy.

\section{Proliferation assay}

Human promyelocytic leukemia cells from cell line HL-60 (ATCC CCL-240) were used as a prototype ATRA-responsive cell line. The cells were grown in RPMI 1640 medium (Sigma Aldrich) supplemented with $2 \mathrm{mM}$ L-glutamine, antibiotics (pen./strept., Sigma Aldrich) and $10 \%$ fetal calf serum (FCS; Invitrogen). The cells were plated onto 96-well plates (Thermo Scientific), $5 \times 10^{3}$ cells/well, and cultivated with various concentrations of the conjugates, ATRA and AtrHy as control. The conjugates and free drugs were dissolved in DMSO at a concentration of $10 \mathrm{mM}$ ATRA or AtrHy, and further dilution was performed using the culture medium. All sample handling was limited to minimal time and lighting. Next, the proliferation was determined using the standard ${ }^{3} \mathrm{H}$-thymidine incorporation assay (Ř́hová et al. 2001). The cells were pulsed with $30 \mathrm{kBq}$ during the last 6 hours of the total three-day cultivation period. All measurements were performed in quadruplicate, and the results were calculated as the percentage of untreated control cells.

\section{Results and Discussion}

In this paper, we present the results of the synthesis, physicochemical characterization and evaluation of preliminary biological activity of polymer conjugates containing covalently bound ATRA 
derivative, AtrHy, as a biologically active compound. A water-soluble polymer carrier was used in this study with the aim to increase the solubility of ATRA, prolong blood circulation within the body, and enable the passive accumulation and controlled release of the ATRA derivative within the solid tumor mass. The local increase of retinoid concentration in the solid tumor should downregulate the accumulation of MDCSs by stimulating their differentiation. Upon changing to a more differentiated status, MDSCs downregulate their immunosuppressive activity. Thus, the proper $\mathrm{CD} 8^{+}$-mediated immune response could be restored. As a suitable polymer carrier, we used linear polymer precursors based on HPMA copolymers. The side chains contained amino groups modified by three different keto acids with varied structures. The difference in the chemical structure in the vicinity of the keto group affects the stability of the pH-sensitive hydrazone bond between the AtrHy derivative and the polymer carrier and could be used to regulate the AtrHy release kinetics, as our observations confirmed.

\section{Synthesis of polymer conjugates}

The polymer precursor Pol was prepared by the controlled RAFT copolymerization of HPMA and APMA-BOC monomers. The copolymer showed characteristics suitable for a polymer carrier in drug delivery, i.e. very narrow dispersity $\mathrm{D}=1.13$ and a molecular weight of $25,000 \mathrm{~g} / \mathrm{mol}$ (Table 1). The removal of the BOC protecting groups did not significantly change the dispersity and molecular weight of the polymer precursor Pol- $\mathrm{NH}_{2}$.

Generally, hydrazone bond is formed between hydrazide and keto groups in mild acidic conditions. To prepare polymer with a $\mathrm{pH}$-sensitive hydrazone bond bound retinoid (AtrHy), the polymer precursor Pol- $\mathrm{NH}_{2}$ and ATRA had to be modified before the final syntheses. The polymer Pol- $\mathrm{NH}_{2}$ was modified with three different keto acids with varying structure, $\mathrm{OPe}, \mathrm{OPB}$ and $\mathrm{COV}$, with the aim of obtaining different release rate of AtrHy under conditions mimicking the body environment. Generally, each keto acid was first activated to its aminoreactive TT-derivate by the carbodiimide coupling method. Afterward, the reactive derivatives were used to modify the amino groups presented on the polymer precursor Pol- $\mathrm{NH}_{2}$. The modification by keto acids did not significantly change the dispersity and molecular weight of the respective polymer precursors. The yield of the reaction varied among the keto acids, being the highest for OPB (91\%) and slightly lower for OPe $(73 \%)$ and $\operatorname{COV}(71 \%)$. The remaining amino groups in polymer precursors Pol-OPe, Pol-OPB and Pol-COV were protected by reaction with acetic anhydride to prevent crosslinking reactions of the amino groups and the keto groups on the polymers.

ATRA was first activated using carbodiimide chemistry and then reacted with an excess of hydrazine hydrate to avoid the bis-modification of hydrazine hydrate. Due to the UV and oxygen sensitivity of ATRA, the reaction was carried out in the dark and under inert conditions. The reaction course was monitored by an HPLC equipped with a DAD detector, and the reaction was stopped upon reaching a high yield.

The final polymer conjugates were prepared by the reaction of AtrHy and the respective polymer precursor containing keto groups (Fig. 1). The attachment of AtrHy lead to an attachment of 9.3\% AtrHy in PolOPe-AtrHy, $8.3 \%$ AtrHy in Pol-OPB-AtrHy and $7.7 \%$ AtrHy in Pol-COV-AtrHy and did not significantly change the molecule weight and dispersity of the polymer systems.

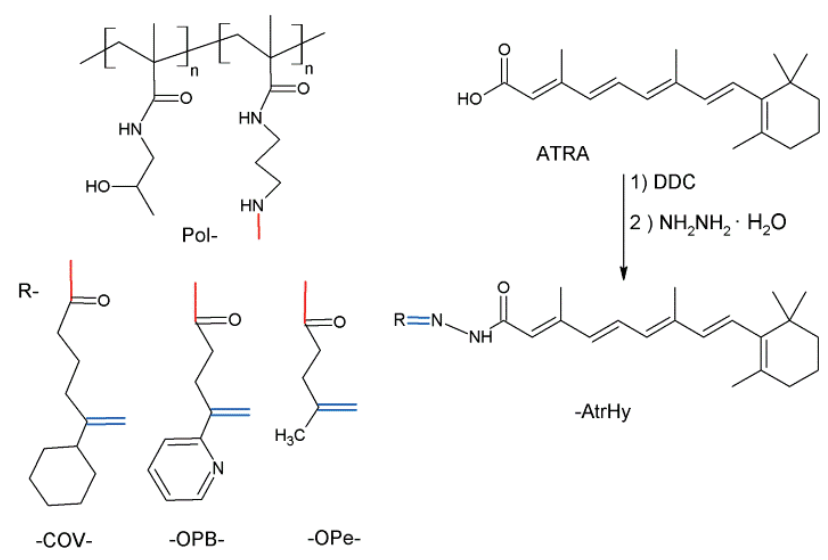

Fig. 1. Schematic structures of polymer conjugates Pol-COVAtrHy, Pol-OPB-AtrHy, Pol-OPe-AtrHy composed of polymer backbone Pol-; keto acid linkers -COV-, -OPB-, -OPe-; and hydrazide derivative AtrHy.

The hydrodynamic size of the polymer systems in aqueous solution is the crucial parameter for their passive accumulation within the solid tumor, where the EPR effect is observed. We determined the solution behavior of all the polymers using dynamic light scattering. Polymer precursors in aqueous solution formed random coils with a hydrodynamic radius of approximately $4 \mathrm{~nm}$. The hydrodynamic radius of the final polymer conjugates increased almost three times 
Table 1. Schematic structures of polymer conjugates Pol-COV-AtrHy, Pol-OPB-AtrHy, Pol-OPe-AtrHy composed of polymer backbone Pol-; keto acid linkers -COV-, -OPB-, -OPe-; and hydrazide derivative AtrHy.

\begin{tabular}{|c|c|c|c|c|c|c|}
\hline Polymer notation & $\begin{array}{l}M_{w} \\
\left(g \cdot \mathbf{m o l}^{-1}\right)\end{array}$ & $\mathbf{M}_{\mathbf{w}} / \mathbf{M}_{\mathbf{n}}$ & $\begin{array}{l}R_{\mathrm{h}} \\
(\mathrm{nm})\end{array}$ & $\begin{array}{l}\text { Linker } \\
\text { (type; \% mol) }\end{array}$ & $\begin{array}{l}-\mathrm{NH}_{2} \\
(\% \mathrm{~mol})\end{array}$ & $\begin{array}{l}\text { AtrHy } \\
\text { (\% wt) }\end{array}$ \\
\hline Pol & 25870 & 1.13 & 4.2 & - & - & - \\
\hline Pol- $\mathrm{NH}_{2}$ & 26820 & 1.11 & 4.3 & - & 8.5 & - \\
\hline Pol-OPe & 27360 & 1.17 & 4.2 & OPe; 6.2 & 0.1 & - \\
\hline Pol-OPB & 29390 & 1.16 & 3.5 & OPB; 7.7 & 0.0 & - \\
\hline Pol-COV & 34770 & 1.08 & 3.7 & $\mathrm{COV} ; 6.0$ & 0.0 & - \\
\hline Pol-OPe-AtrHy ${ }^{a)}$ & 32900 & 1.22 & 10.4 & - & - & 9.3 \\
\hline Pol-OPB-AtrHy ${ }^{a)}$ & 33920 & 1.19 & 12.0 & - & - & 8.3 \\
\hline Pol-COV-AtrHy & 35680 & 1.10 & 7.4 & - & - & 7.7 \\
\hline
\end{tabular}

a) Final polymer-AtrHy conjugate

after attachment of AtrHy (Table 1). We hypothesize that the high hydrophobicity of AtrHy contributes to the amphiphilic character of the conjugate, resulting in aqueous solution in the formation of small aggregates or, more probably, polymer micelles. The increase in $R_{h}$ seems to be dependent on the combination of the hydrophobicity of AtrHy and the linkage used. The highest $R_{h}$ was observed for the OPB linkage $(12.0 \mathrm{~nm})$ and the smallest for the COV linkage $(7.4 \mathrm{~nm})$. A detailed evaluation of the solution behavior of the polymer conjugates is under way.

\section{Release of AtrHy}

We selected three keto acids with different structures with the goal of modifying the stability of the hydrazone bond between the AtrHy derivative and the polymer carrier. The stability and rate of AtrHy release were measured under conditions mimicking the $\mathrm{pH}$ of human blood $(\mathrm{pH}$ 7.4) or the intracellular conditions of lysosomes ( $\mathrm{pH}$ 5.0). The amount of AtrHy released was calculated by the integration of the areas of UV signal peaks $(A=363 \mathrm{~nm})$ obtained by HPLC for free (released) and polymer-bound AtrHy. The conjugates containing $\mathrm{OPe}, \mathrm{COV}$ and OPB keto acid spacers showed different hydrazone bond stability, ranging from very stable (OPB) to less stable (OPe). The key parameter identifying a polymer conjugate as suitable for drug delivery in the organism is its stability in the blood stream. We found that Pol-OPe-AtrHy was less stable at $\mathrm{pH}$ 7.4, as almost $50 \%$ of AtrHy was released within $24 \mathrm{~h}$ of incubation. In contrast, the polymer conjugates Pol-COV-AtrHy and Pol-OPB-AtrHy seemed to be more stable in the conditions mimicking the blood stream, with $10 \%$ of
AtrHy released from Pol-COV-AtrHy and $2 \%$ from PolOPB-AtrHy after 24 hours at $\mathrm{pH} 7.2$ (Fig. 2). A similar release profile was found after $24 \mathrm{~h}$ incubation at $\mathrm{pH}$ 5.0, the release was the fastest from the OPe-containing conjugate (more than $70 \%$ ), moderate for the COVcontaining conjugate $(50 \%)$ and the lowest for the OPB conjugate $(10 \%)$. Thus, the most promising candidate among the three conjugates studied seems to be PolCOV-AtrHy, which showed high stability in the environment mimicking the blood stream and quite rapid degradation of the hydrazone bond at $\mathrm{pH}$ 5.0.

\section{Biological activity}

To obtain a polymer conjugate with a $\mathrm{pH}$ sensitive release profile, ATRA had to be modified before attachment to the polymer carrier to its hydrazide derivative AtrHy. The influence of changes in the structure of ATRA (to AtrHy) on the biological properties of the drug was evaluated. The ability of AtrHy and AtrHy bound to the polymer carrier to induce the differentiation of myeloid cells was compared to original ATRA in a proliferation assay using ${ }^{3} \mathrm{H}$-thymidine incorporation and human HL-60 cells. It is known that these cells strongly downregulate their proliferation during the process of differentiation (Takahashi et al. 2014). As expected, the free ATRA showed the strongest capacity to inhibit HL-60 proliferation, whilst AtrHy inhibited the proliferation moderately less. All the conjugates showed lower capacity in inhibiting HL-60 proliferation (Fig. 3). However, this activity remained significant, being the most prominent in the conjugate Pol-OPe-AtrHy and lowest in Pol-OPBAtrHy. This result is consistent with the release profile of AtrHy, as the release of AtrHy derivative from Pol-OPe- 


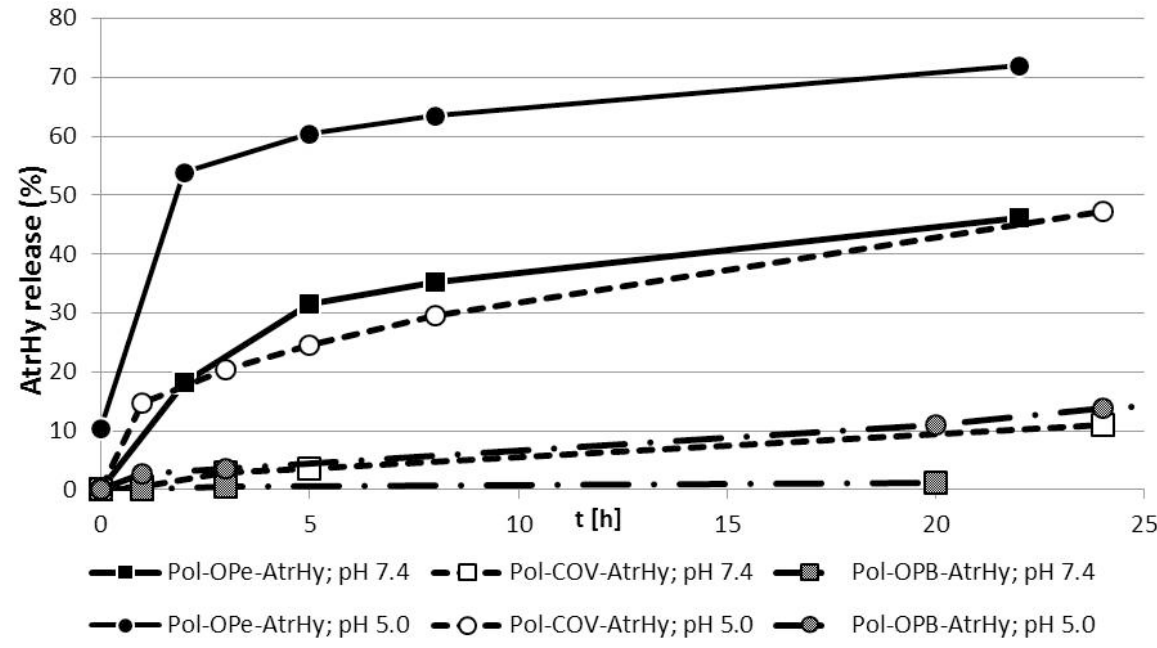

Fig. 2. Release of AtrHy from polymer conjugates. Release kinetics of AtrHy from micellar polymer conjugates: PolOPe-AtrHy, Pol-OPB-AtrHy, Pol-COVAtrHy at $\mathrm{pH} 5.0$ and $\mathrm{pH} 7.4$.
AtrHy is the fastest under both the low pH-simulating conditions in lysosomes $(\mathrm{pH}$ 5.0) and in conditions mimicking the blood stream ( $\mathrm{pH} 7.4)$. However, Pol-OPeAtrHy releases the ATRA derivatives to a very great extent in the buffer at blood $\mathrm{pH}$; therefore, the $\mathrm{COV}$ analog would be more suitable for in vivo application. The Pol-COVAtrHy conjugate exhibited to similar extent activity toward HL-60 cells when compared to the OPe-containing conjugate, whilst its release kinetics was more favorable. No cytostatic respective cytotoxic activity against murine tumor cells, such as T cell lymphoma EL4 or 4T1 carcinoma, was observed using proliferation or metabolic activity assays (data not shown). This fact points to a potential use of the conjugates to modulate the tumor microenvironment rather than to directly dampen the proliferation of tumor growth.

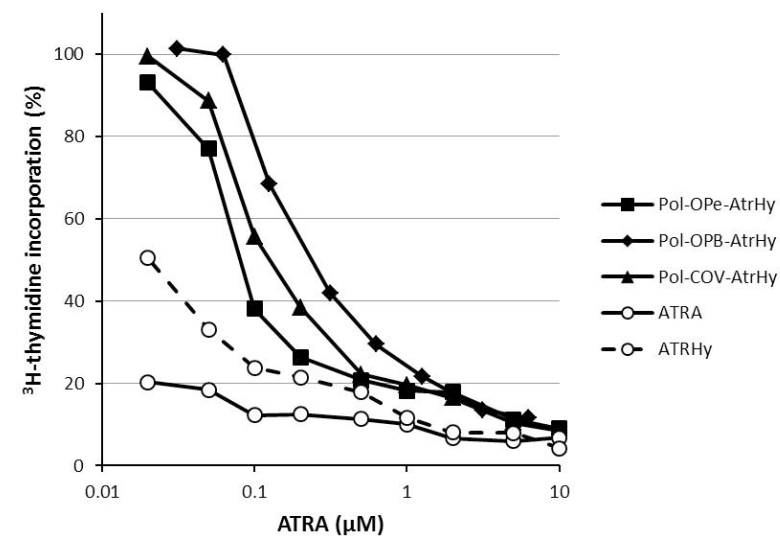

Fig. 3. In vitro inhibition of the proliferation of ATRA-responsive $\mathrm{HL}-60$ cells caused by ATRA, AtrHy derivative and AtrHycontaining conjugates. The $\mathrm{HL}-60$ cells were incubated with the polymer conjugates Pol-OPe-AtrHy, Pol-OPB-AtrHy, Pol-COVAtrHy, with ATRA and AtrHy as controls, at several concentrations. Proliferation was detected by standard ${ }^{3} \mathrm{H}$-thymidine incorporation after three days of cultivation.

\section{Conclusions}

We have described the design, synthesis and evaluation of the physicochemical characterization and biological activity of several HPMA-based polymerretinoid conjugates that were tailor-made for immunotherapy of the solid tumors. All the polymer carriers were synthesized using the RAFT polymerization technique to obtain highly defined polymer systems with low dispersity and the ability of passive tumor targeting. In the conjugates, a hydrazide derivative of ATRA was attached to polymer carriers differing in the structure of the side-chain spacer via the hydrolytically unstable hydrazone bond. In aqueous solution the polymer-AtrHy conjugates, due to the AtrHy hydrophobicity, formed supra-molecular aggregates or micelles, what can highly support passive accumulation within the solid tumor due to the EPR effect. The conjugates were relatively stable at the $\mathrm{pH}$ of blood (7.4) and released active drug under mildly acidic conditions ( $\mathrm{pH} 5.0$ ), a model of the lysosomal environments of cells. The derivatization of ATRA to its hydrazide form slightly decreased its original biological activity, but in vitro data proved that AtrHy is still able to slow down the proliferation of HL-60 cells at concentrations which we suppose achievable in vivo. Moreover, the polymer-AtrHy conjugates showed decreased but still reasonable capacity to inhibit the proliferation of HL-60 cells. Thus, we can conclude that the polymer-AtrHy conjugate could be a suitable candidate for further in vivo studies as an immuno-modulator in solid tumor immunotherapy.

\section{Conflict of Interest}

There is no conflict of interest. 


\section{Acknowledgements}

This work was supported by the Ministry of Education,

Youth and Sports of CR within the National
Sustainability Program II (Project BIOCEV-FAR LQ1604).

\section{References}

CHYTIL P, ETRYCH T, KŘIIŽ J, SUBR V, ULBRICH K: N-(2-Hydroxypropyl)methacrylamide-based polymer conjugates with $\mathrm{pH}$-controlled activation of doxorubicin for cell-specific or passive tumour targeting. Synthesis by RAFT polymerisation and physicochemical characterisation. Eur J Pharm Sci 41: 473-482, 2010.

DOLCETTI L, MARIGO I, MANTELLI B, PERANZONI E, ZANOVELLO P, BRONTE V: Myeloid-derived suppressor cell role in tumor-related inflammation. Cancer Lett 267: 216-225, 2008.

ETRYCH T, CHYTIL P, JELÍNKOVÁ M, ŘÍHOVÁ B, ULBRICH K: Synthesis of HPMA copolymers containing doxorubicin bound via a hydrazone linkage. Effect of spacer on drug release and in vitro cytotoxicity. Macromol Biosci 2: 43-52, 2002.

ETRYCH T, JELÍNKOVÁ M, ŘÍHOVÁ B, ULBRICH K: New HPMA copolymers containing doxorubicin bound via pH-sensitive linkage: Synthesis and preliminary in vitro and in vivo biological properties. $J$ Control Release 73: 89-102, 2001.

FANG J, NAKAMURA H, MAEDA H: The EPR effect: Unique features of tumor blood vessels for drug delivery, factors involved, and limitations and augmentation of the effect. Adv Drug Deliv Rev 63: 136-151, 2011.

FATTAHI A, GOLOZAR MA, VARSHOSAZ J, SADEGHI HM, FATHI M: Preparation and characterization of micelles of oligomeric chitosan linked to all-trans retinoic acid. Carbohydr Polym 87: 1176-1184, 2012.

GABRILOVICH DI, NAGARAJ S: Myeloid-derived-supressor cells as regulators of the immune system. Nat Rev Immunol 9: 162-174, 2009.

JEONG Y IL, SONG JG, KANG SS, RYU HH, LEE YH, CHOI C, SHIN BA, KIM KK, AHN KY, JUNG S: Preparation of poly(DL-lactide-co-glycolide) microspheres encapsulating all-trans retinoic acid. Int $J$ Pharm 259: 79-91, 2003.

KAPADIA CH, PERRY JL, TIAN S, LUFT JC, DESIMONE JM: Nanoparticulate immunotherapy for cancer. J Control Release 219: 167-180, 2015.

KOPEČEK J, KOPEČKOVÁ P: HPMA copolymers: Origins, early developments, present, and future. Adv Drug Deliv Rev 62: 122-149, 2010.

KUSMARTSEV S, CHENG F, YU B, NEFEDOVA Y, SOTOMAYOR E, LUSH R: All- trans -retinoic acid eliminates immature myeloid cells from tumor-bearing mice and improves the effect of vaccination. Cancer Res $\mathbf{6 3}$ : 4441-4449, 2003.

KUSMARTSEV S, SU Z, HEISER A, DANNULL J, ERUSLANOV E, KÜBLER H, YANCEY D, DAHM P, VIEWEG J: Reversal of myeloid cell - mediated immunosuppression in patients with metastatic renal cell carcinoma. Clin Cancer Res 14: 8270-8278, 2008.

LIM SJ, LEE MK, KIM CK: Altered chemical and biological activities of all-trans retinoic acid incorporated in solid lipid nanoparticle powders. J Control Release 100: 53-61, 2004.

MIRZA N, FISHMAN M, FRICKE I, DUNN M, NEUGER AM, FROST TJ, LUSH RM, ANTONIA S, GABRILOVICH DI: All-trans-retinoic acid improves differentiation of myeloid cells and immune response in cancer patients. Cancer Res 66: 9299-9307, 2006.

NEFEDOVA Y, FISHMAN M, SHERMAN S, WANG X, BEG AA, GABRILOVICH DI: Mechanism of all-trans retinoic acid effect on tumor-associated myeloid-derived suppressor cells. Cancer Res 67: 11021-11028, 2007.

OSTRAND-ROSENBERG S, SINHA P: Myeloid-derived suppressor cells: linking inflammation and cancer. J Immunol 182: 4499-4506, 2009.

ŘÍHOVÁ B, ETRYCH T, PECHAR M, JELÍNKOVÁ M, ŠTASTNÝ M, HOVORKA O, KOVÁŘ M, ULBRICH K: Doxorubicin bound to a HPMA copolymer carrier through hydrazone bond is effective also in a cancer cell line with a limited content of lysosomes. $J$ Control Release 74: 225-232, 2001. 
SERAFINI P: Myeloid derived suppressor cells in physiological and pathological conditions: The good, the bad, and the ugly. Immunol Res 57: 172-184, 2013.

SEYMOUR LW, MIYAMOTO Y, MAEDA H, BRERETON M, STROHALM J, ULBRICH K, DUNCAN R: Influence of molecular weight on passive tumour accumulation of a soluble macromolecular drug carrier. Eur $J$ Cancer 31A: 766-770, 1995.

SRIVASTAVA MK, ERSSON Å, ZHU L, HARRIS-WHITE M, LEE JM, DUBINETT S, SHARMA S: Myeloid suppressor cells and immune modulation in lung cancer. Immunotherapy 4: 291-304, 2012.

ŠUBR V, SIVÁK L, KOZIOLOVÁ E, BRAUNOVÁ A, PECHAR M, STROHALM J, KABEŠOVÁ M, ŘÍHOVÁ B, ULBRICH K, KOVÁŘ M: Synthesis of Poly[N -(2-hydroxypropyl)methacrylamide] conjugates of inhibitors of the $\mathrm{ABC}$ transporter that overcome multidrug resistance in doxorubicin-resistant P388 cells in vitro. Biomacromolecules 15: 3030-3043, 2014.

TAKAHASHI H, HATTA Y, IRIYAMA N, HASEGAWA Y, UCHIDA H, NAKAGAWA M, MAKISHIMA M, TAKEUCHI J, TAKEI M: Induced differentiation of human myeloid leukemia cells into M2 macrophages by combined treatment with retinoic acid and 1 $\alpha, 25$-dihydroxyvitamin D3. PLoS One 9: 1-9, 2014.

TIWARI MD, MEHRA S, JADHAV S, BELLARE JR: All-trans retinoic acid loaded block copolymer nanoparticles efficiently induce cellular differentiation in HL-60 cells. Eur J Pharm Sci 44: 643-652, 2011.

UGEL S, DELPOZZO F, DESANTIS G, PAPALINI F, SIMONATO F, SONDA N, ZILIO S, BRONTE V: Therapeutic targeting of myeloid-derived suppressor cells. Curr Opin Pharmacol 9: 470-481, 2009.

ULBRICH K, ŠUBR V: Structural and chemical aspects of HPMA copolymers as drug carriers. Adv Drug Deliv Rev 62: 150-166, 2010.

ULBRICH K, ŠUBR V, STROHALM J, PLOCOVÁ D, JELÍNKOVÁ M, ŘÍHOVÁ B: Polymeric drugs based on conjugates of synthetic and natural macromolecules. I. Synthesis and physico-chemical characterisation. J Control Release 64: 63-79, 2000.

VANNEMAN M, DRANOFF G: Combining immunotherapy and targeted therapies in cancer treatment. Nat Rev Cancer 12: 237-251, 2012.

WEIDE B, MARTENS A, ZELBA H, STUTZ C, DERHOVANESSIAN E, DI GIACOMO AM, MAIO M, SUCKER A, SCHILLING B, SCHADENDORF D, ET AL.: Myeloid-derived suppressor cells predict survival of patients with advanced melanoma: comparison with regulatory T cells and NY-ESO-1- or melan-A-specific T cells. Clin Cancer Res 20: 1601-1609, 2014.

WICKI A, WITZIGMANN D, BALASUBRAMANIAN V, HUWYLER J: Nanomedicine in cancer therapy: Challenges, opportunities, and clinical applications. J Control Release 200: 138-157, 2015. 